\title{
Crafting Engaging Programming Experiences for Young People in GLAM Spaces: The iOi-Sphere
}

\author{
Alcwyn Parker \\ Games Academy \\ Falmouth University \\ Penryn, Cornwall, UK \\ alcwyn.parker@falmouth.ac.uk
}

\begin{abstract}
The renewed emphasis on computing at schools in the UK sheds light on challenges with programming pedagogy; for example, poor recruitment and retention. This poster introduces the physical programming education installation at the Institute of Imagination: the iOi-Sphere. It then outlines future research into a supporting development environment and curriculum for ages 5-16.
\end{abstract}

\section{CCS CONCEPTS}

- Social and professional topics $\rightarrow$ K-12 education; • Humancentered computing $\rightarrow$ Interaction design theory, concepts and paradigms; - Software and its engineering $\rightarrow$ Programming teams;

\section{ACM Reference Format:}

Alcwyn Parker and Michael James Scott. 2018. Crafting Engaging Programming Experiences for Young People in GLAM Spaces: The iOiSphere. In Proceedings of 23rd Annual ACM Conference on Innovation and Technology in Computer Science Education (ITiCSE'18). ACM, New York, NY, USA, 1 page. https://doi.org/10.1145/3197091.3205827

\section{INTRODUCTION}

The national curriculum in the United Kingdom strives to help pupils leverage computational thinking and creativity to understand the world [1]. Recent initiatives emphasize basic programming from age 5 to 16 . However, still few young people choose to pursue a qualification in computing. Instilling enthusiasm for code and empowering young people to feel they can achieve will be key to the success of the new curriculum [3]. To this end, our research explores the role, affordances, and impact of physical computing artefacts in gallery, library, archive, and museum (GLAM) spaces to encourage and inspire the next generation of computing professionals.

\section{PROTOTYPE}

iOiSphere, commissioned by the Institute of Imagination and completed in 2017, acts as a digital fascinator for school visits. It is a 1-meter diameter hemisphere; the surface, of which, is covered in 202 toggle switches. Each individual custom designed toggle switch has an embedded LED and audio response, acting as both input

Permission to make digital or hard copies of part or all of this work for personal or classroom use is granted without fee provided that copies are not made or distributed for profit or commercial advantage and that copies bear this notice and the full citation on the first page. Copyrights for third-party components of this work must be honored.

For all other uses, contact the owner/author(s).

ITiCSE'18, July 2-4, 2018, Larnaca, Cyprus

(C) 2018 Copyright held by the owner/author(s)

ACM ISBN 978-1-4503-5707-4/18/07 \$ \$15.00

https://doi.org/10.1145/3197091.3205827

\author{
Michael James Scott \\ Games Academy \\ Falmouth University \\ Penryn, Cornwall, UK \\ michael.scott@falmouth.ac.uk
}

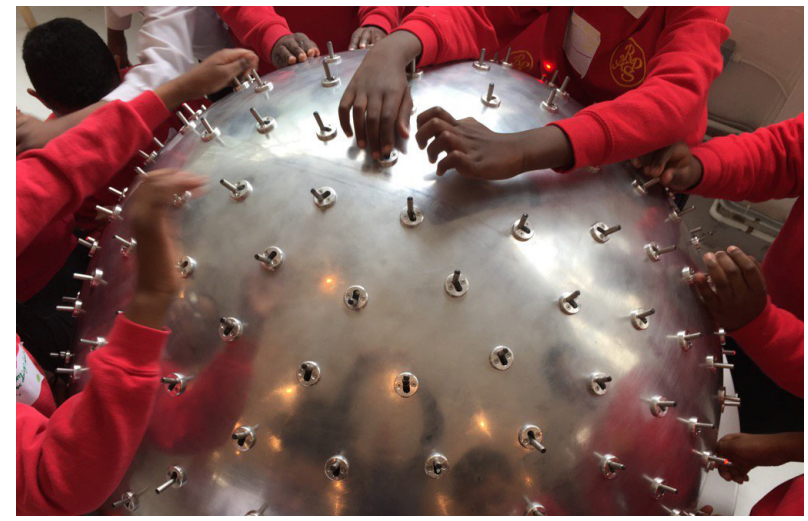

Figure 1: iOi Sphere in action at the Institute of Imagination and output. As a standalone artefact, iOiSphere hosts several games that are playable in parallel to encourage co-creative and casual play. Beyond the default behavior, a USB port in the side of the sphere allows pupils on school visits to upload code that they have developed themselves to modify its behavior.

The next stage in this research involves creating a web-based integrated development environment (IDE) with a simple visual scripting interface, a simulator of iOiSphere, and a small curriculum that contains tutorials on how to program the sphere. Programs created in the classroom using the IDE can then be downloaded as Arduino sketches and uploaded to the iOiSphere as part of the activities included in a school visit. A user-centered approach is key to avoid typical pitfalls in this field [2]. The impact of the engagement with iOiSphere will be measured through a small questionnaire integrated into the process of uploading a program to the sphere and with consideration for the stages outlined by Resnick for creative thinking [4].

\section{REFERENCES}

[1] Neil C. C. Brown, Sue Sentance, Tom Crick, and Simon Humphreys. 2014. Restart: The Resurgence of Computer Science in UK Schools. Trans. Comput. Educ. 14, 2, Article 9 (June 2014), 22 pages. https://doi.org/10.1145/2602484

[2] Alexandria K. Hansen, Ashley Iveland, Cameron Carlin, Danielle B. Harlow, and Diana Franklin. 2016. User-Centered Design in Block-Based Programming: Developmental \& Pedagogical Considerations for Children. In Proceedings of the The 15th International Conference on Interaction Design and Children (IDC '16). ACM, New York, NY, USA, 147-156. https://doi.org/10.1145/2930674.2930699

[3] Kate Howland, Judith Good, Judy Robertson, and Andrew Manches. 2015. Every Child a Coder? Research Challenges for a 5-18 Programming Curriculum. In Proceedings of the 14th International Conference on Interaction Design and Children (IDC '15). ACM, New York, NY, USA, 470-473. https://doi.org/10.1145/2771839. 2771954

[4] Mitchel Resnick. 2007. All I Really Need to Know (About Creative Thinking) I Learned (by Studying How Children Learn) in Kindergarten. In Proceedings of the 6th ACM SIGCHI Conference on Creativity \& Cognition (C\&C '07). ACM, New York, NY, USA, 1-6. https://doi.org/10.1145/1254960.1254961 